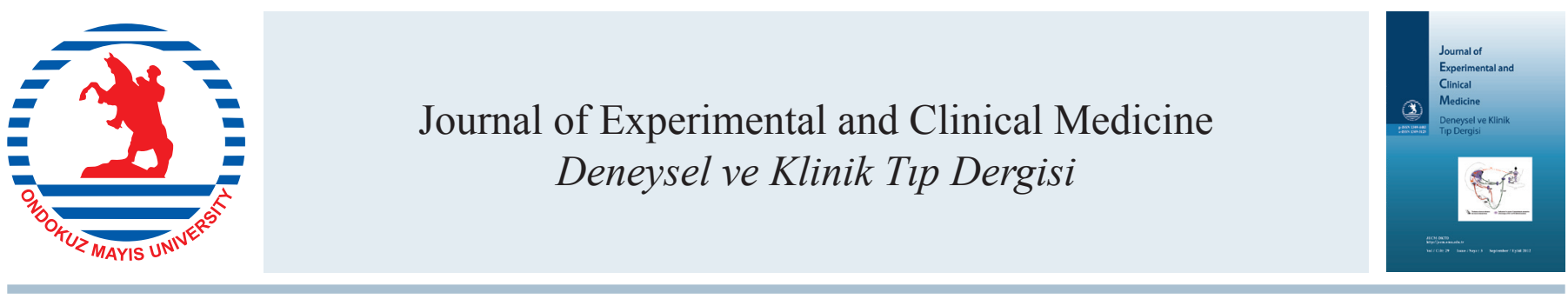

Review

doi: $10.5835 /$ jecm.omu.29.03.002

\title{
The clinical approach to the hypertensive disorders of pregnancy
}

\author{
Gebeliğin hipertansif hastalıklarına klinik yaklaşım
}

\author{
Rahman Yavuz*a, Demet Yavuz ${ }^{\text {b }}$ \\ ${ }^{a}$ Department of Family Medicine, Medical Faculty, Ondokuz Mayı University, Samsun, Turkey \\ ${ }^{b}$ Clinic of Nephrology, Sakarya Training and Research Hospital, Sakarya, Turkey
}

\begin{tabular}{|c|c|}
\hline ARTICLI & \\
\hline Article $\mathbf{H}$ & \\
\hline Received & $20 / 06 / 2012$ \\
\hline Accepted & $02 / 07 / 2012$ \\
\hline
\end{tabular}

\section{* Correspondence to:}

Rahman Yavuz

Department of Family Medicine, Medical

Faculty, Ondokuz Mayıs University,

Samsun, Turkey

e-mail: rahmanyavuz55@hotmail.com

\section{Keywords:}

Hypertension

Pregnancy

Clinical approach

Hypertensive disorders

Preeclampsia

Gestational hypertension

\section{ABSTRACT}

Hypertensive disorders in pregnancy remain a major cause of maternal, fetal and neonatal morbidity and mortality not only in developing but also in developed countries. Hypertension in pregnancy can be due to one of several distinct disorders, including gestational hypertension, preexisting chronic hypertension, preeclampsia-eclampsia, preeclampsia superimposed upon chronic hypertension.

J. Exp. Clin. Med., 2012; 29:171-176

\section{ÖZET}

Gebelikte hipertansif hastalıklar sadece gelişmiş ülkelerde değil aynı zamanda gelişmekte olan ülkelerde de maternal, fetal ve neonatal mortalite ve morbiditenin önde gelen nedenidir. Gebelikte hipertansiyon gestasyonel hipertansiyon, kronik hipertansiyon, preeklampsi-eklampsi, kronik hipertansiyon üzerine eklenmiş preeklampsi gibi hastalıklardan biri nedeniyle oluşabilmektedir.

J. Exp. Clin. Med., 2012; 29:171-176

\author{
Anahtar Kelimeler: \\ Hipertansiyon \\ Gebelik \\ Klinik yaklaşım \\ Hipertansif hastalıklar \\ Preeklampsi \\ Gestasyonel hipertansiyon
}

(C) $2012 \mathrm{OMU}$

\section{Introduction}

Hypertension is the most common medical complication of pregnancy, affecting approximately $10 \%$ of all pregnancies, where it is the second leading cause of maternal death and markedly increases the incidence of preterm birth, intrauterine growth restriction, placental abruption, and perinatal mortality (Elena et al., 2009).

\section{Systemic changes in pregnancy: Cardiovascular chan- ges}

The total blood volume increases by $40 \%$ to $50 \%$ by the 32 nd week of gestation, caused by primarily increase in plasma volume (Poppas et al., 1997). The cardiac output is estimated to increase by approximately $30 \%$ to $50 \%$ above baseline (Thornburg et al., 2000). The maternal heart rate increases between 10 and 20 beats/minute (Mabie et al., 1994). Blood pressure begins to decrease in the first trimester, reaches a nadir in mid-pregnancy, and returns to baseline before term. Supine hypotensive syndrome is a condition that affects up to $\% 8$ of pregnant women and occurs mainly after the late part of second trimester. This leads to hypotension, nausea, dizziness and fainting (Suresh and Radfar, 2004). 


\section{Diagnosis and classification of hypertension in preg- nancy}

Hypertension in pregnancy is defined as systolic blood pressure greater than or equal to $140 \mathrm{mmHg}$ and/or diastolic blood pressure greater than or equal to $90 \mathrm{mmHg}$. These measurements should be confirmed by repeated readings over several hours. Elevations of both systolic and diastolic blood pressures have been associated with adverse fetal outcome and therefore both are important (Seligman, 1987). Severe hypertension in pregnancy is defined as a systolic blood pressure greater than or equal to $160 \mathrm{mmHg}$ and/or diastolic blood pressure greater than or equal to $110 \mathrm{mmHg}$ (Mancia et al., 2009). It is generally acknowledged that severe hypertension should be lowered promptly, albeit carefully, to prevent cerebral haemorrhage and hypertensive encephalopathy. There are four major hypertensive disorders that occur in pregnant women, including; gestational hypertension, pre-existing chronic hypertension, preeclampsia-eclampsia, preeclampsia superimposed upon chronic hypertension (Marik, 2009).

\section{a. Pre-existing chronic hypertension}

Pre-existing chronic hypertension is one of the most common medical conditions complicating pregnancy, affecting about $3 \%$ of pregnant women. Primary idiopathic hypertension is the most common cause of chronic hypertension in pregnancy (ACOG Committee, 2001). Pre-existing hypertension is a primary disorder in $90-95 \%$ of cases and may be either essential $(90 \%)$ or secondary to some identifiable underlying disorder, such as renal parenchymal disease (e.g., polycystic kidneys, glomerular or interstitial disease), renal vascular disease (e.g., renal artery stenosis, fibromuscular dysplasia), endocrine disorders (e.g., adrenocorticosteroid or mineralocorticoid excess, pheochromocytoma, hyperthyroidism or hypothyroidism, growth hormone excess, hyperparathyroidism), coarctation of the aorta, or oral contraceptive use. Pregnant women may have a diagnosis of pre-existing chronic hypertension before conception, or a presumptive diagnosis may be made in the presence of sustained hypertension before 20 weeks of gestation. A systolic blood pressure of $\geq 140 \mathrm{mmHg}$ or a diastolic blood pressure of $\geq 90 \mathrm{mmHg}$ on 2 occasions at least 4 hours apart is necessary for diagnosis. Pre-existing hypertension is a strong risk factor for the development of preeclampsia. Adverse maternal and perinatal outcomes occur primarily because of superimposed preeclampsia. Women with severe untreated chronic hypertension (systolic blood pressure is greater than or equal to $170 \mathrm{mmHg}$ and/or diastolic blood pressure is greater than or equal to 110 $\mathrm{mmHg}$ ) are at risk for adverse maternal outcomes secondary to end-organ damage (Lowe et al., 2009).

\section{b. Gestational hypertension}

Gestational hypertension is usually defined as having a blood pressure higher than 140/90 without the presence of protein in the urine and diagnosed after 20 weeks of gestation. The pathophysiology of gestational hypertension is unknown. Gestational hypertension may, however, be a harbinger of chronic hypertension later in life. It occurs in about 6 percent of pregnancies (Yoder et al., 2009). Women who present in pregnancy beyond 20 weeks with increased blood pressure without proteinuria or a known history of chronic hypertension are classified as having gestational hypertension (Sibai,
2003). The gestational hypertension risk is higher if there are including; first pregnancy, obesity, over 30 years of age, having a personal or family history of gestational hypertension or preeclampsia, having chronic renal failure or diabetes mellitus, carrying twins or higher multiples. Gestational hypertension is considered severe if there is sustained elevations in systolic blood pressure to at least $160 \mathrm{~mm} \mathrm{Hg}$ and/or in diastolic blood pressure to at least $110 \mathrm{~mm} \mathrm{Hg}$ for at least 6 hours (ACOG Committee on Practice Bulletins-Obstetrics, 2001).

The diagnosis is changed to: Preeclampsia; if proteinuria develops, chronic hypertension; if blood pressure elevation persists $\geq 12$ weeks postpartum, transient hypertension of pregnancy; if blood pressure returns to normal by 12 weeks postpartum. Thus, reassessment up to 12 weeks postpartum is necessary to establish a final definitive diagnosis. In general, the majority of cases of mild gestational hypertension develop at or beyond 37 weeks' gestation, and thus pregnancy outcome is similar or superior to that seen in women with normotensive pregnancies. Both gestational age at delivery and birth weight in these pregnancies are higher than those in normotensive pregnancies (Sibai et al., 2000). Maternal and perinatal morbidities are substantially increased in women with severe gestational hypertension. In addition, the rates of abruptio placentae, preterm delivery, and small for gestational age of infants in these women are similar to those seen in women with severe preeclampsia. Therefore, these women should be managed as if they had severe preeclampsia (Buchbinder et al., 2002).

\section{c. Preeclampsia}

Preeclampsia is a disorder of widespread vascular endothelial malfunction and vasospasm that occurs after 20 weeks gestation and can present as late as 4-6 weeks postpartum. Preeclampsia has been known as 'The Disease of Theories', as the exact course of events that lead to the clinical syndrome have not been elucidated. Several etiologies have been proposed but most have not withstood the test of time. Some of these suggested causes include abnormal trophoblast invasion of uterine vessels, immunologic intolerance between fetoplacental and maternal tissues, inflammatory changes of pregnancy, and genetic abnormalities (Sibai et al., 2005). The incidence of preeclampsia in the United States is estimated to range from $2 \%$ to $6 \%$ in healthy, nulliparous women (Vatten and Skjaerven, 2004). In developing nations, the incidence of the disease is reported to be $4-18 \%$, with hypertensive disorders being the second most common obstetric cause of stillbirths and early neonatal deaths in these countries (Ngoc et al., 2006).

Preeclampsia is defined as high blood pressure and excess protein in the urine after 20 weeks of pregnancy in a woman who previously had normal blood pressure. The diagnostic threshold for proteinuria is $300 \mathrm{mg}$ in a 24-hour urine specimen. Severe preeclampsia is indicated by more substantial blood pressure elevations and a greater degree of proteinuria. Other features of severe preeclampsia include oliguria, cerebral or visual disturbances, and pulmonary edema or cyanosis listed in Table 1, risk factors for preeclampsia listed in Table 2 (ACOG Committee on Practice Bulletins-Obstetrics, 2001).

Often, women who are diagnosed with preeclampsia do not feel sick. Symptoms of preeclampsia can include; swel- 


\section{Table 1. Diagnostic criteria for severe preeclampsia}

Blood pressure: $160 \mathrm{~mm} \mathrm{Hg}$ or higher systolic or $110 \mathrm{~mm} \mathrm{Hg}$ or higher diastolic on two occasions at least six hours apart in a woman on bed rest

Proteinuria: $5 \mathrm{~g}$ or more of protein in a 24-hour urine collection or $3+$ or greater on urine dipstick testing of two random urine samples collected at least four hours apart

Other features: Oliguria, cerebral or visual disturbances, pulmonary edema, epigastric or right upper quadrant pain, impaired liver function, thrombocytopenia, intrauterine growth restriction

\begin{tabular}{l} 
Table 2. Risk factors for preeclampsia \\
Maternal-specific factors \\
\hline Age greater than 35 years \\
Age less than 20 years \\
Black race \\
Family history of preeclampsia \\
Nulliparity \\
Preeclampsia in a previous pregnancy \\
Specific medical conditions: gestational diabetes, type I diabetes, \\
obesity, chronic hypertension, renal disease, thrombophilias \\
Stress \\
Pregnancy-associated factors \\
Chromosomal abnormalities \\
Hydatidiform mole \\
Hydrops fetalis \\
Multifetal pregnancy \\
Oocyte donation or donor insemination \\
Structural congenital anomalies \\
Urinary tract infection
\end{tabular}

ling of the hands and face/eyes (edema), weight gain (More than $2 \mathrm{~kg}$ per week, sudden weight gain over 1-2 days). Systemic involvement leads to abdominal pain, headache, seizure, oliguria, and shortness of breath. Right upper quadrant and epigastric abdominal pain occurs as a result of liver edema and subcapsular hematoma or hemorrhage. The HELLP syndrome (hemolysis, elevated liver enzymes, and low platelets) sometimes accompanies liver dysfunction and is a marker of severity in preeclampsia. HELLP can also lead to a coagulopathy that causes bleeding from mucosal membranes and leads to death in $2 \%$ to $24 \%$ of cases. Neurologic findings are the result of cerebral edema, usually described as the reversible posterior leukoencephalopathy syndrome, which is associated with headache, vomiting, confusion, visual abnormalities, and seizures. Renal involvement can eventually include renal failure; it is usually caused by acute tubular necrosis from hemorrhage or sepsis and improves after resolution of preeclampsia. Shortness of breath can be the result of pulmonary edema resulting from capillary leak. While pulmonary edema is a serious complication of preeclampsia, the most common cause of death in preeclampsia and eclampsia is cerebrovascular hemorrhage, occurring in up to $50 \%$ to $65 \%$ of cases (Lipstein et al., 2003). The hemoglobin and hematocrit may be elevated due to hemoconcentration, or in more severe cases, there may be anemia secondary to hemolysis. Thrombocytopenia is often present. Fibrin split products and decreased coagulation factors may be detected. Uric acid is usually elevated above $6 \mathrm{mg} / \mathrm{dL}$. Serum creatinine is most often normal $(0.6-0.8 \mathrm{mg} / \mathrm{dL})$ but may be elevated in severe preeclampsia. Although hepatic abnormalities occur in about $10 \%$ of patients, the bilirubin is usually below $5 \mathrm{mg} /$ $\mathrm{dL}$ and the aspartate aminotransferase below 500 IU. Alkali- ne phosphatase may increase 2-to 3-fold. Lactate dehydrogenase may be quite high. Blood glucose and electrolytes are normal. Urinalysis reveals proteinuria and occasional hyaline casts (Norwitz and Funai, 2008). If unrecognized, preeclampsia can progress HELLP syndrome. HELLP syndrome is a severe microcirculatory disturbance during pregnancy, associated with pre-eclampsia, but it may occur also without it. In HELLP maternal morbidity and mortality have increased. Such patients often present with right upper quadrant and epigastric pain and a peripheral blood smear consistent with a microangiopathic hemolytic anemia. There may be decrements in the platelet count and increments in the transaminase and lactic acid dehydrogenase enzymes. This is a lifethreatening emergency that requires prompt delivery of the baby. The only effective means to treat the syndrome during pregnancy is termination of pregnancy (Norwitz and Funai, 2008). Another serious complication of preeclampsia is development of seizures or coma. This is known as eclampsia.

Prevention of eclampsia is one of the primary goals in the management of preeclampsia. During labor, the management goals are to prevent seizures and control hypertension. Antihypertensive therapy is urgently indicated when systolic blood pressures reach $160 \mathrm{~mm} \mathrm{Hg}$ or diastolic blood pressures reach $105 \mathrm{~mm} \mathrm{Hg}$. Generally, 5 to $10 \mathrm{mg}$ doses of hydralazine or labetalol can be administered every 15 minutes until a systolic blood pressure between 140 and $160 \mathrm{~mm}$ $\mathrm{Hg}$ and a diastolic blood pressure between 90 and $110 \mathrm{~mm}$ $\mathrm{Hg}$ is achieved (Sibai, 2005). Methyldopa, calcium channel blockers, and labetalol are widely used and appear to be safe. $\beta$-Blockers may be associated with an increased risk of smallfor-gestational-age infants and fetal bradycardia. Hydralazine, which had been extensively used in the past for severe hypertension in pregnancy, is associated with more maternal hypotension, cesarean sections, placental abruption, maternal oliguria, and lower Apgar scores and is no longer considered a proven firstline treatment for severe hypertension in pregnancy, although it is still commonly used (Magee et al., 2003). Angiotensin-converting enzyme inhibitors and angiotensin II receptor blockers should be avoided due to their teratogenic effects. There is a lack of randomized, controlled studies large enough to determine a preferred antihypertensive agent, and first-choice agents have been determined by clinical experience (Magee et al., 1999). Intravenous agents are generally preferred in the acute setting with severe disease, but most patients can be managed with oral agents.

\section{d. Preeclampsia superimposed upon chronic hypertensi- on}

There is ample evidence that preeclampsia can occur in women who are already hypertensive and that the prognosis for mother and fetus is much worse with both conditions than with either alone. Distinguishing superimposed preeclampsia from worsening chronic hypertension tests the skills of the clinician. For clinical management, the principles of high sensitivity and unavoidable overdiagnosis are appropriate, especially with advancing gestational age. The diagnosis of superimposed preeclampsia is highly likely with the following findings; in women with documented hypertension and no proteinuria before 20 weeks' gestation, in women with hypertension and proteinuria before 20 weeks' gestation (A sudden increase in proteinuria, a sudden increase in blood pressure 
in a woman whose blood pressure has previously been well controlled, objective evidence of involvement of multiple organ systems, such as platelet count $<100.000 / \mathrm{mm}^{3}$, an increase in liver transaminases to abnormal levels, or sudden worsening of renal function) (Roberts and Funai, 2009).

\section{e. Eclampsia}

Eclampsia is defined as the occurrence of one or more seizures superimposed on preeclampsia. (Mattar and Sibai, 2000). It typically occurs during or after the 20th week of gestation or in the postpartum period. An eclamptic seizure occurs in 2 to 3 percent of severely preeclamptic women not receiving anti-seizure prophylaxis; the seizure rate is estimated to be between 0 and 0.6 percent in women with mild preeclampsia (Sibai, 2004). The incidence of eclampsia has been relatively stable at 1.6 to 10 cases per 10,000 deliveries in developed countries (Liu et al., 2011). In developing countries, however, the incidence varies widely: From 6 to 157 cases per 10.000 deliveries (Eke et al., 2011). Nonwhite, nulliparous women from lower socioeconomic backgrounds are the group at highest risk of developing eclampsia. Peak incidence is in the teenage years and low twenties, but there is also an increased incidence in women over 35 years of age. The exact cause of seizures in women with eclampsia is not known. The following two hypotheses have been proposed; cerebral overregulation in response to high systemic blood pressure results in vasospasm of cerebral arteries, underperfusion of the brain, localized ischemia/infarction, and intracellular edema, loss of autoregulation of cerebral blood flow in response to high systemic pressure results in hyperperfusion, endothelial damage, and vasogenic edema (Morriss et al., 1997).

The aims of treatment are to terminate the seizure, prevent recurrence, control hypertension and prevent maternal and fetal hypoxia. If the seizure is witnessed, maintenance of airway patency and prevention of aspiration should be the first responsibilities of management. Supplemental oxygen ( 8 to $10 \mathrm{~L} / \mathrm{min}$ ) via a face mask has been recommended to treat hypoxemia due to hypoventilation during the convulsive episode. Magnesium sulfate is the anticonvulsant drug of choice for the prevention and treatment of eclampsia. Typical dosing of magnesium sulfate is a loading dose of $6 \mathrm{~g}$ over 15 to 20 minutes, followed by a maintenance dose of $2 \mathrm{~g} / \mathrm{hr}$ by continuous infusion (Sibai, 2005). If the seizure is prolonged, IV diazepam ( $2 \mathrm{mg} /$ minute to a maximum of $10 \mathrm{mg}$ ) or clonazepam (1-2 mg over 2-5 minutes) may be given (Lowe et al., 2009). Phenytoin should not be used for eclampsia prophylaxis or treatment unless there is a contraindication to magnesium sulfate or it is ineffective. The use of antiepileptic drugs is associated with a greater baseline risk of fetal malformations during pregnancy (The Magpie Trial Collaborative Group, 2002). Although clinical trials have not adequately addressed the question of how aggressively to lower an eclamptic patient's blood pressure, many experts consider a reasonable goal to be a systolic pressure of 140 to $155 \mathrm{mmHg}$ and diastolic pressure of 90 to $105 \mathrm{mmHg}$. In women with extremely severe hypertension $(\geq 180 / 120 \mathrm{mmHg})$, a diastolic goal of 100 to $105 \mathrm{mmHg}$ should be achieved within two to six hours, with the maximum initial (within 10 to 20 minutes) fall in blood pressure not exceeding 25 percent of the presenting value. Options for initial treatment include; hydralazine beginning with $5 \mathrm{mg}$ intravenously, followed by 5 to $10 \mathrm{mg}$ boluses as necessary every 20 minutes, labetalol beginning with 10 or $20 \mathrm{mg}$ intravenously followed by doubling the dose at 10-minute intervals up to $80 \mathrm{mg}$ for a maximum total cumulative dose of 220 to $230 \mathrm{mg}$. An additional therapeutic option in these women is nicardipine beginning with $5 \mathrm{mg} /$ hour intravenously and increased by $2.5 \mathrm{mg} /$ hour every 5 to 15 minutes to a maximum dose of $15 \mathrm{mg} /$ hour (Vaughan and Delanty, 2000).

\section{Evaluation and management of hypertension in preg- nancy}

Ideally, evaluation of women with chronic hypertension or with a history of hypertension in a previous pregnancy should begin before conception. The clinician should focus on the possibility of secondary hypertension, assessment of renal function and hypertensive target-organ damage, detecting underlying diabetes or renal disease, and eliciting a family history of pregnancy complications. Women should be a baseline laboratory evaluation that includes, electrolytes, measurement of hepatic transaminases, uric acid urinalysis and urine culture, 24-hour urine for evaluation of creatinine clearance, protein and albumin excretion, and complete blood count with platelets. Women should then be seen every 2 to 3 weeks for measurement of blood pressure and urine protein, and for fetal assessment as indicated (Umans, 2007). Blood pressure assessment and the search for proteinuria form the cornerstone of antenatal screening of all pregnant women for pre-eclampsia. Women who have been defined as at increased risk of pre-eclampsia are monitored more closely, often in a specialised obstetric clinic. Part of the risk assessment includes Doppler ultrasound evaluation of the uterine arteries around the time of the fetal anomaly scan at 20-22 weeks and blood analysis (James and Nelson-Piercy, 2004).

\section{a. Nonpharmacological management}

Nonpharmacological management should be recommended for all women with hypertension in pregnancy. Dietary salt restriction does not affect the incidence of gestational hypertension or preeclampsia specifically, and is not recommended (European Society of Hypertension and European Society of Cardiology, 2007). Possible and safe methods of nonpharmacological management in pregnancy are as follows; smoking cessation, prohibition on alcohol consumption, restriction of physical activity, bed rest in left lateral position, rich in vitamins, microelements and proteins, light diet (SzczepaniakChickel et al., 2007) It should be noted that prolonged bed rest may be associated with complications such as thrombosis, muscle atrophy or bone demineralization. (Meher et al., 2005).

\section{b. Hypertensive disorders medical manangement}

Antihypertensive drug therapy is recommended for pregnant women with systolic blood pressures of 160 to $180 \mathrm{~mm} \mathrm{Hg}$ or higher and diastolic blood pressures of 105 to $110 \mathrm{~mm} \mathrm{Hg}$ or higher.Table 3 summarizes the agents most commonly used for chronic blood pressure control in pregnancy (Umans, 2007). Most antihypertensive agents used in pregnancy are designated as "category C". Treatment with methyldopa has been reported to prevent subsequent progression to severe hypertension in pregnancy and does not seem to have adverse effects on uteroplacental or fetal hemodynamics or on fe- 
tal well being (Podymow and August, 2012). Labetolol has gained wide acceptance in pregnancy. Oral administration is considered safe and effective as methyldopa, although neonatal hypoglycemia is reported at high doses (Pickels et al., 1989). Both nifedipine a nondihydropyridine calcium channel blocker and verapamil are not associated with teratogenic risks to fetus exposed in first trimester. Maternal adverse effects with nifedipine include tachycardia, palpitations, peripheral edema, headaches, and facial flushing. Nifedipine does not seem to cause a detectable decrease in uterine blood flow (Mustafa et al., 2012). Hydralazine: Selectively relaxes arteriolar smooth muscle by an as yet unknown mechanism. The most important indication is severe hypertension or a thirdline agent in control of refractory hypertension. Hydralazine has been used in all trimesters of pregnancy, and data have not shown an association with teratogenicity, although neonatal thrombocytopenia and lupus have been reported (Table 3) (Mustafa et al., 2012).
Table 3. Oral antihypertensives used in pregnancy

\begin{tabular}{ll} 
Drug (FDA risk) & Dose \\
\hline Methyldopa (B) & $0.5-3.0 \mathrm{~g} / \mathrm{d}$ in 2-3 divided doses \\
$\begin{array}{l}\text { Labetolol (C) or other beta } \\
\text { receptor antagonists }\end{array}$ & $200-2400 \mathrm{mg} / \mathrm{d}$ in 2-3 divided doses \\
Hydralazine (C) & $50-300 \mathrm{mg} / \mathrm{d}$ in 2-4 divided doses \\
Nifedipine (C) & $30-120 \mathrm{mg} / \mathrm{d}$ of a slow-release \\
Contraindicated & \\
\hline ACE inhibitors and AT1 receptor antagonists (D) \\
Use after first trimester can lead to fetopathy, oligohydramnios, growth \\
retardation, and neonatal anuric renal failure, which may be fatal
\end{tabular}

\section{Conclusion}

Hypertension is the most common medical problem encountered in pregnancy. These women are at higher risk for severe complications such as abruptio placentae, cerebrovascular accident, organ failure, and disseminated intravascular coagulation. The fetus is at risk for intrauterine growth retardation, prematurity, and intrauterine death.

\section{REFERENCES}

ACOG Committee, 2001. Chronic hypertension in pregnancy. Obstet. Gynecol. 98, 177-185.

ACOG Committee on Practice Bulletins-Obstetrics, 2001. Diagnosis and management of pre-eclampsia and eclampsia. Obstet. Gynecol. 98, 159-167.

Buchbinder, A., Sibai, B.M., Caritis, S., Macpherson, C., Hauth, J., Lindheimer, M.D., 2002. Adverse perinatal outcomes are significantly higher in severe gestational hypertension than in mild preeclampsia. Am. J. Obstet. Gynecol. 186, 66-71.

Eke, A.C., Ezebialu, I.U., Okafor, C., 2011. Presentation and outcome of eclampsia at a tertiary center in South East Nigeria-a 6-year review. Hypertens. Pregnancy. 30, 125.

Elena, V.K., Callaghan, A.C., William, M., 2009. Hypertensive disorders and severe obstetric morbidity in the United States. Obstetrics \& Gynecology. 113, 1299-1306.

European Society of Hypertension-European Society of Cardiology, 2007. Guidelines for the management of arterial hypertension. J. Hypertens. $25,1105-1187$.

James, P.R., Nelson-Piercy, C., 2004. Management of hypertension before, during, and after pregnancy. Heart. 90, 1501.

Lipstein, H., Lee, C.C., Crupi, R.S., 2003. A current concept of eclampsia. Am. J. Emerg. Med. 21, 223-226.

Liu, S., Joseph, K.S., Liston, R.M., Bartholomew, S., Walker, M., León, J.A., Kirby, R.S., Sauve, R., Kramer, M.S., 2011. Incidence, risk factors, and associated complications of Eclampsia. Obstet. Gynecol. 118, 987.

Lowe, S.A., Brown, M.A., Dekker, G.A., Gatt, S., McLintock, C.K., McMahon, L.P., Mangos, G., Moore, M.P., Muller, P., Paech, M., Walters, B., 2009. Guidelines for the management of hypertensive disorders of pregnancy 2008. Aust. N.Z. J. Obstet. Gynaecol. 49, $242-246$.

Mabie, W.C., Di Sessa, T.G., Crocker, L.G., Sibai, B.M., Arheart, K.L., 1994. A longitudinal study of cardiac output in normal human pregnancy. Am. J. Obstet. Gynecol. 170, 849-856.

Magee, L.A., Ornstein, M.P., von Dadelszen, P., 1999. Fortnightly review: Management of hypertension in pregnancy. B.M.J. 318, $1332-1336$.

Magee, L.A., Cham, C., Waterman, E.J., Ohlsson, A., von Dadelszen, P., 2003. Hydralazine for treatment of severe hypertension in pregnancy: Metaanalysis. B.M.J. 327, 955-960.

Mancia, G., De Backer, G., Dominiczak, A., Cifkova, R., Fagard, R., Germano, G., Grassi, G., Heagerty, A.M., Kjeldsen, S.E., Laurent, S., Narkiewicz, K., Ruilope, L., Rynkiewicz, A., Schmieder, R.E., Boudier, HA., Zanchetti, A., 2007. ESH-ESC Practice guidelines for the management of arterial hypertension: ESH-ESC Task force on the management of arterial hypertension. J. Hypertens. 25, 1751-1762.

Marik, P.E., 2009. Hypertensive disorders of pregnancy. Postgrad. Med. 121, 69-76.

Mattar, F., Sibai, B.M., 2000. Eclampsia. VIII. Risk factors for maternal morbidity. Am. J. Obstet. Gynecol. 182, $307-312$.

Meher, S., Abalos, E., Carroli, G., 2005. Bed rest with or without hospitalisation for hypertension during pregnancy. Cochrane DB. Syst. Rev. 19,4 .

Morriss, M.C., Twickler, D.M., Hatab, M.R., Clarke, G.D., Peshock, R.M., Cunningham, F.G., 1997. Cerebral blood flow and cranial magnetic resonance imaging in eclampsia and severe preeclampsia. Obstet. Gynecol. 89, 561.

Mustafa, R., Ahmed, S., Gupta, A., Venuto, R.C., 2012. A comprehensive review of hypertension in pregnancy. J. Pregnancy. 2012.

Ngoc, N.T., Merialdi, M., Abdel-Aleem, H., Carroli, G., Purwar, M., Zavaleta, N., Campódonico, L., Ali, M.M., Hofmeyr, G.J., Mathai, M., Lincetto, O., Villar, J., 2006. Causes of stillbirths and early neonatal deaths: Data from 7993 pregnancies in six developing countries. B. World Health Organ. 84, 699-705.

Norwitz, E.R., Funai, E.F., 2008. Expectant management of severe preeclampsia remote from term: Hope for the best, but expect the worst. Am. J. Obstet. Gynecol. 199, 209-212.

Pickles, C.J., Symonds, E.M., Broughton Pipkin F., 1989. The fetal outcome in a randomized double-blind controlled trial of labetalol versus placebo in pregnancy-induced hypertension. Br. J. Obstet. Gynaecol. 96, 38-43.

Podymow, T., August, P., 2012. Update on the use of antihypertensive drugs in pregnancy. Hypertension. 51, 960-969.

Poppas, A., Shroff, S.G., Korcarz, C.E., Hibbard, J.U., Berger, D.S., Lindheimer, M.D., Lang, R.M., 1997. Serial assessment of the cardiovascular system in normal pregnancy. Role of arterial compliance and pulsatile arterial load. Circulation. 95, 2407-2415.

Report of the National High Blood Pressure Education Program Working Group on High Blood Pressure in Pregnancy, 2000. Am. J. Obstet. Gynecol. 183, 1-22.

Roberts, J.M., Funai, E.F., 2009. Pregnancy-Related Hypertension. Maternal-Fetal Medicine: Principles and Practice 6th ed. R.K., Creasy, R., 
Resnik, J.D, Iams, C.J., Lockwood, T.R., Moore, eds. Saunders Elsevier, Philadelphia. 652-653.

Seligman, S., 1987. Which blood pressure? Br. J. Obstet. Gynaecol. 94, 497-498.

Sibai, B.M., Caritis, S., Hauth, J., Lindheimer, M.D., MacPherson, C., Klebanoff, M., VanDorsten, J.P., Landon, M., Miodovnik, M., Paul, R., Meis, P., Thurnau, G., Dombrowski, M., Roberts, J., McNellis, D., 2000. Hypertensive disorders in twin versus singleton gestations. National Institute of Child Health and Human Development Network of Maternal-Fetal Medicine Units. Am. J. Obstet. Gynecol. 182, $938-942$.

Sibai, B.M., 2003. Diagnosis and management of gestational hypertension and preeclampsia. Obstet. Gynecol. 102, 181-192.

Sibai, B.M., 2004. Magnesium sulfate prophylaxis in preeclampsia: Lessons learned from recent trials. Am. J. Obstet. Gynecol. $190,1520$.

Sibai, B.M., 2005. Diagnosis, prevention, and management of eclampsia. Obstet. Gynecol. 105, 402-410.

Sibai, B.M., Dekker, G., Kupferminc, M., 2005. Preeclampsia. Lancet. 365, 785-799.

Suresh, L., Radfar, L., 2004. Pregnancy and lactation. Oral Surg Oral Med. Oral Pathol. Oral Radiol. Endod. 97, 672-682.

Szczepaniak-Chickel, L., Breborowicz, G.H., Tykarski, A., 2007. Treatment of arterial hypertension in pregnancy. Archives of perinatal Medicine. 13,10 .

The Magpie Trial Collaborative Group, 2002. Do women with pre-eclampsia, and their babies, benefit from magnesium sulphate? The Magpie Trial: A randomised placebo-controlled trial. Lancet. 359, 1877-1890.

Thornburg, K.L., Jacobson, S.L., Giraud, G.D., Morton, M.J., 2000. Hemodynamic changes in pregnancy. Semin. Perinatol. 24 , 11-14.

Umans, J.G., 2007. Hypertension in Pregnancy. Comprehensive Hypertension. 1st ed. Gregory, Y.H., Lip John, E. Mosby Elseiver, Philadelphia. 674-676.

Vatten, L.J., Skjaerven, R., 2004. Is pre-eclampsia more than one disease? B.J.O.G. 111, 298-302.

Vaughan, C.J., Delanty, N., 2000. Hypertensive emergencies. Lancet. 356, 411.

Yoder, S.R., Thornburg, L.L., Bisognano, J.D., 2009. Hypertension in pregnancy and women of childbearing age. Am. J. Med. 122, 890-895. 